\title{
Cyanamide-Induced Granulocytopenia
}

\author{
Miho Ajima, Kensuke Usuki*, Atsuyuki Igarashi**, Ryo OKaZaki, \\ Kumiko Hamano, Akio Urabe* and Yasuo TotsuKa**
}

We report a 64-year-old male with granulocytopenia and dermatitis due to cyanamide treatment. We administered cyanamide for alcoholism. After about one month he suffered from scaly erythema over his whole body and granulocytopenia (granulocyte; $140 / \mu \mathrm{l}$ ) with maturation arrest in bone marrow. After cessation of cyanamide and the start of granulocyte colonystimulating factor administration, the skin eruption ameliorated gradually, and the peripheral blood granulocyte counts increased. Cyanamide showed positive results in the drug lymphocyte stimulation test $(\mathbf{1 9 8 \%})$ ) and the patch test led to the diagnosis of granulocytopenia and dermatitis induced by cyanamide. After restarting glibenclamide and diazepam administration, his granulocytopenia did not reoccur. To our knowledge, this is the first report of a case with granulocytopenia induced by cyanamide.

(Internal Medicine 36: 640-642, 1997)

Key words: adverse effect, side effect, drug allergy, drug eruption, alcoholics

\section{Introduction}

Cyanamide (Cyanamide ${ }^{\circledR}$; Yoshitomi Co., Ltd., Tokyo) is a widely used antabuse for alcoholics. The mechanism of cyanamide to discourage alcohol consumption is inhibition of the complete catabolism of alcohol resulting in the accumulation of acetaldehyde (1). Contact dermatitis (2) and liver injury (3) have been reported as adverse effects of this agent. Here, we report a case with granulocytopenia induced by this drug. To our knowledge, this is the first case report on granulocytopenia induced by cyanamide.

\section{Case Report}

A 64-year-old male had received oral hypoglycemic agents for diabetes mellitus since 1964, and he had drunk about $360 \mathrm{ml}$ of sake (Japanese spirits containing $16.5 \%$ alcohol) every day for 32 years. Because of bad glucose control with a hemoglobin $\mathrm{A}_{1 \mathrm{c}}$ level of $10 \%$ due to alcohol intake, we started to administer $100 \mathrm{mg}$ of cyanamide and $2 \mathrm{mg}$ of diazepam in addition to glibenclamide on July 24, 1995. After 3 weeks, he began to feel general fatigue, and skin eruption emerged over the lower abdomen and thigh. On September 1, he had scaly erythema over his whole body with a body temperature of $37^{\circ} \mathrm{C}$ and peripheral blood examination showed a leukocyte count of 7,500/ $\mu \mathrm{l}$ (neutrophils; $81.5 \%$, lymphocytes; $10.9 \%$, monocytes;
$6.8 \%$, eosinophils; $0.5 \%$, basophils; $0.3 \%$ ), a hemoglobin concentration of $15.0 \mathrm{~g} / \mathrm{dl}$, and a platelet count of $15.3 \times 10^{4} / \mu \mathrm{l}$. He continued to receive cyanamide and the hypoglycemic agent every day, and he was admitted to our hospital on September 13, 1995. He had candidiasis in his oral cavity and scaly erythema over the whole body (Fig. 1) with a body temperature of $37.7^{\circ} \mathrm{C}$. Peripheral blood examination showed a leukocyte count of $1,400 / \mu \mathrm{l}$ (band cells; $2.5 \%$, segmented cells; $7.5 \%$, lymphocytes; $44.0 \%$, monocytes; $45 \%$, eosinophils; $0 \%$, basophils; $0 \%$ ), a hemoglobin concentration of $13.8 \mathrm{~g} / \mathrm{dl}$, and a platelet count of $14.7 \times 10^{4} / \mu 1$. The CRP level was $0.3 \mathrm{mg} / \mathrm{ml}$, and $\mathrm{IgE}$ level was $156 \mathrm{U} / \mathrm{ml}$. Antinuclear antibody test was negative. Bone marrow examination showed normocellular marrow with maturation arrest (Fig. 2). As he had no history of recurrent infections, we diagnosed as drug-induced granulocytopenia and dermatitis. We ceased all medication including glibenclamide, cyanamide, and diazepam, and we started the subcutaneous administration of granulocyte colony-stimulating factor at a daily dose of $75 \mu \mathrm{g}$. Skin eruption ameliorated gradually, and after 6 days of a lministration, the leukocyte count increased to $7,900 / \mu 1$ with $67 \%$ granulocytes. Drug lymphocyte stimulation test was positive for cyanamide $(198 \%)$ and negative for diazepam $(125 \%)$ and glibenclamide $(112 \%)$. In addition, the results of the patch test were also positive for cyanamide (Fig. 3) and negative for diazepam and glibenclamide. After 2 days of patch test of cyanamide, eosinophils in peripheral blood increased to

From the Division of Endocrinology and Metabolısm, *the Division of Hematology and **the Division of Dermatology, Kanto-Teishın Hospital, Tokyo Received for publication January 13, 1997, Accepted for publication May 30, 1997

Reprint requests should be addressed to Dr Yasuo Totsuka, the Division of Endocrinology and Metabolısm, Kanto-Teishın Hospital, 5-9-22 Higashi-Gotanda, Shinagawa-ku, Tokyo 141 


\section{Granulocytopenia due to Cyanamide}

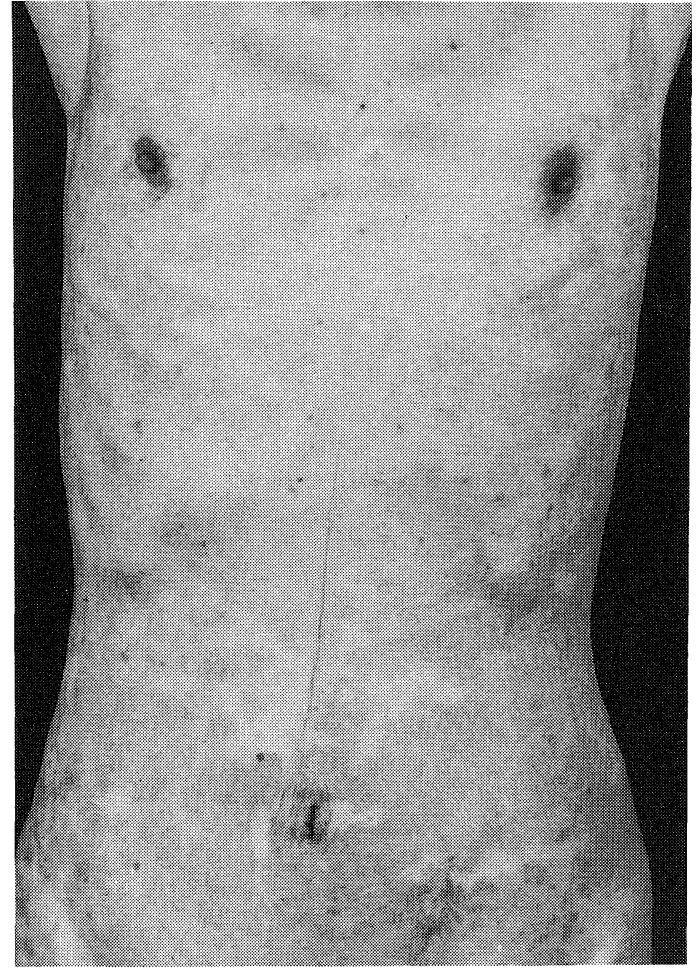

Figure 1. Scaly erythema over the whole body.

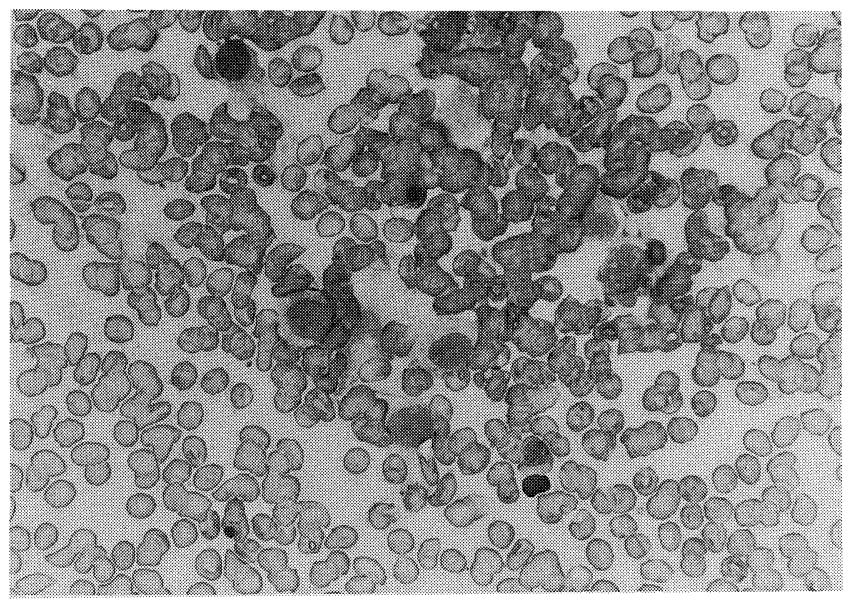

Figure 2. Wright-Giemsa stained bone marrow aspiration specimens show "maturation arrest" $(\times 400)$.

$19.8 \%$. Thus, the diagnosis of granulocytopenia and dermatitis induced by cyanamide was made. After 2 months he had no recurrence of granulocytopenia while receiving glibenclamide and diazepam (Fig. 4).

\section{Discussion}

We present a case with skin eruption and granulocytopenia during cyanamide treatment for alcoholism. Cessation of the

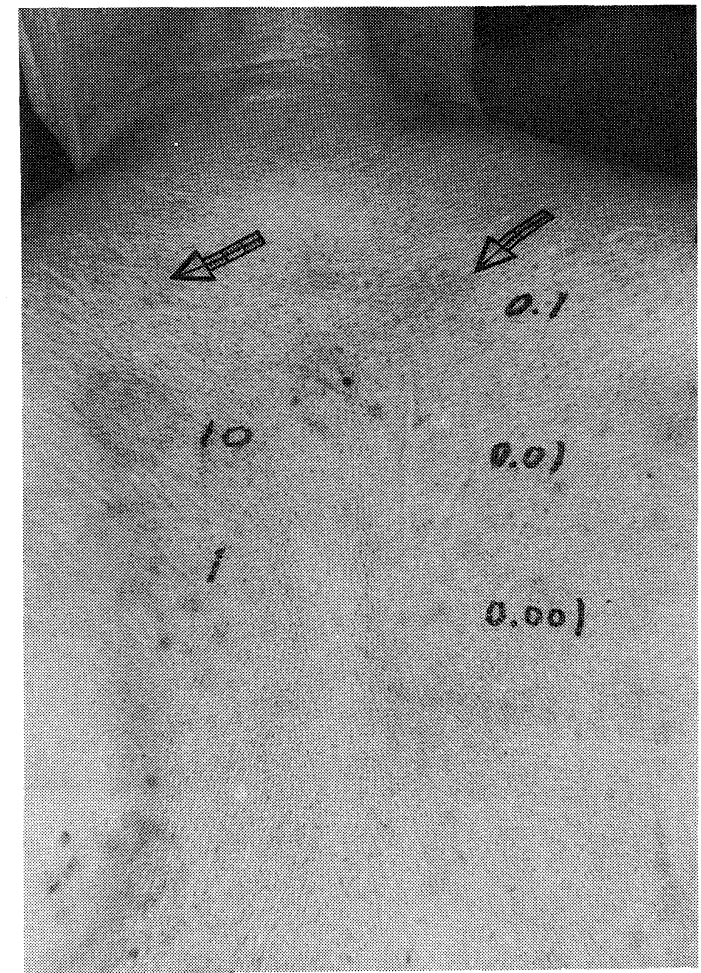

Figure 3. Patch test. Numbers indicate concentrations of injected cyanamide. The preservative agent, methyl parahydroxybenzoate, was used as a negative control the upper left arrow. Cyanamide was positive from $0.1 \mathrm{mg} / \mathrm{ml}$ to $10 \mathrm{mg} / \mathrm{ml}$.

drug administration ameliorated the skin eruption and granulocytopenia, and both drug lymphocyte test and patch test were positive for cyanamide. These findings led us to the diagnosis of dermatitis and granulocytopenia induced by cyanamide. The mechanism of exfoliative erythema is related to a type IV immune reaction. Contact dermatitis was reported as a adverse of cyanamide, and its mechanism is also related to a type IV immune reaction. In addition the patch test was positive for cyanamide in the present case. Thus, exfoliative erythema in this case seems to be the result of a type IV immune reaction against cyanamide. On the other hand, for the causes of druginduced granulocy topenia, known are immune mechanism, e.g. in Quinidine (4) and non-immune mechanisms, e.g. anti-thyroid medication (5). Here, since the drug lymphocyte stimulation test was positive for cyanamide, an immune mechanism against the drug seemed to be involved also in the granulocytopenia in the present case. In addition, Coombs' test was negative, this granulocytopenia seemed to be a case of Type IV reaction. To our knowledge, this is the first report of a case with granulocytopenia induced by this agent. It is necessary to pay particular attention when using cyanamide. 
AJImA et al
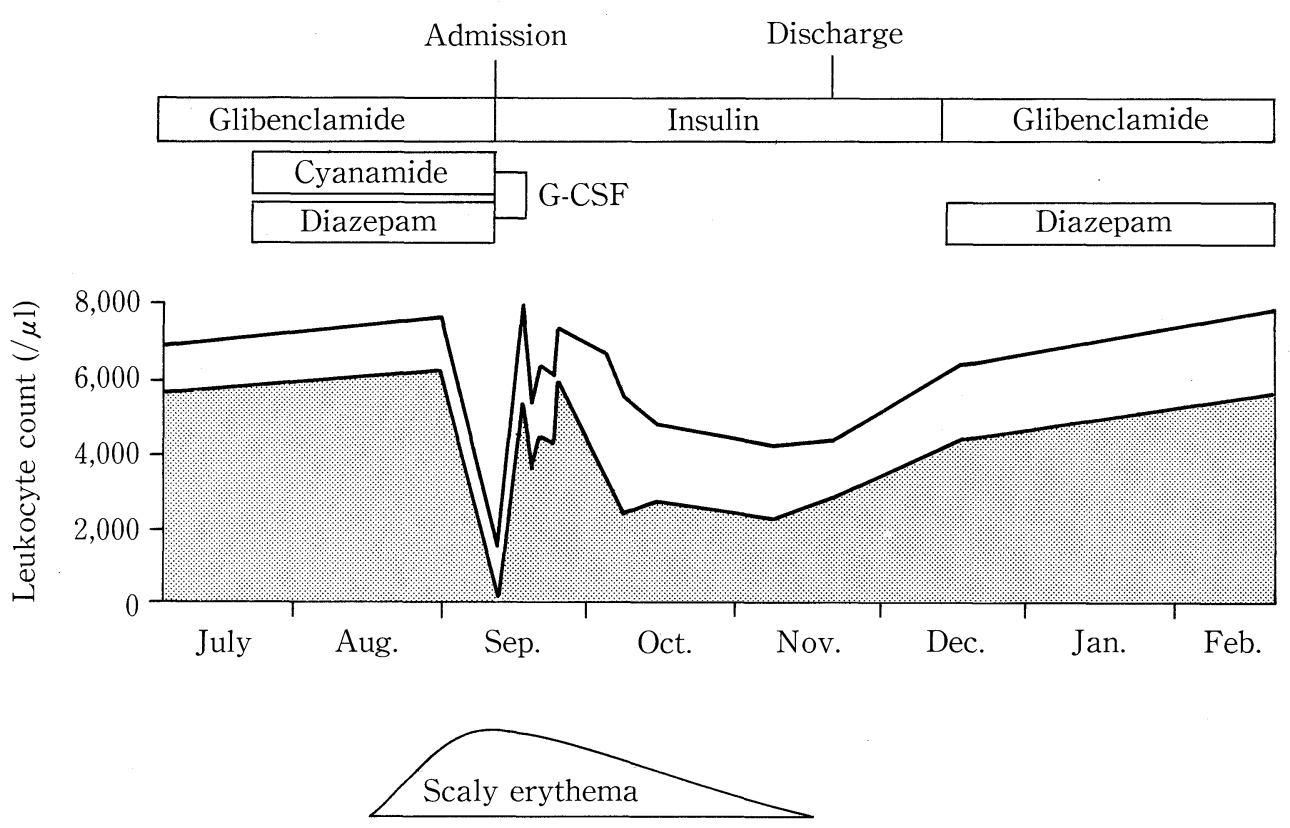

Figure 4. Clinical course. Shaded area indicates the granulocyte counts, and open area indicates leukocytes. All medication was ceased on September 13, 1995 and the administration of granulocyte colony-stimulating factor was started; then scaly erythema and granulocytopenia were ameliorated.

\section{References}

1) Ando H, Fuwa I. Effects of cyanamide on alcohol dehydrogenase and aldehyde dehydrogenase. J Biochem 50: 416, 1961.

2) Conde-Salazar L, Guimaraens D, Romero L, Harto A. Allergic contact dermatitis to cyanamide (carbodiimide). Contact Dermatitis 7:329, 1981.

3) Vazquez JJ, Cervera S. Cyanamide-induced liver injury in alcoholics.
Lancet i: 361, 1980 (letter).

4) Stroncek DF, Vercellotti GM, Hammerschmidt DE, Christie DJ, Shankar RA, Jacob HS. Characterization of multiple quinine-dependent antibodies in a patient with episodic hemolytic uremic syndrome and immune agranulocytosis. Blood 80: 241, 1992.

5) Tajiri J, Noguchi S, Murakami T, Murakami N. Antithyroid drug-induced agranulocytosis. The usefulness of routine white blood cell count monitoring. Arch Intern Med 150: 621, 1990. 